\title{
Perioperative antimicrobial prophylaxis in surgery and adherence to guidelines
}

\author{
Nandkishore Jaiswal ${ }^{1}$, Sujata Dudhgoankar ${ }^{2}$, Kavita M. Jaiswal ${ }^{3, *}$, Latesh Raghute ${ }^{4}$, Lohit S Vaishnao \\ ${ }^{1,2}$ Professor \& HOD, ${ }^{3}$ Associate Professor, ${ }^{4}$ Assistant Professor, ${ }^{5}$ Student, ${ }^{1}$ Dept. of Surgery, ${ }^{2-4}$ Dept. of Pharmacology, \\ Government Medical College, Gondia, Maharashtra, India
}

*Corresponding Author:

Email: jaiswalkavita37@yahoo.com

\begin{abstract}
Introduction: Surgical Antimicrobial Prophylaxis (SAP) lowers post-operative surgical site infection (SSI) if used with American Society of Health-System Pharmacists (ASHP) guidelines.

Objective: The present study was carried out with the aim to assess the rational use of antibiotics for prevention of SSI and to look for adherence to ASHP guidelines.

Materials and Method: This was a prospective study done in 228 patients in surgical ward/ICU who received antibiotics for surgical prophylaxis.

Results: There was unnecessary SAP pre-operatively in $22.80 \%$ respondents. Post-operatively $10.08 \%$ patients received single antibiotic, $79.39 \%$ received two, $14.91 \%$ received three, one received four antimicrobials. Antibiotics were used for procedures where antibiotic prophylaxis is not indicated There was appropriate antimicrobial selection in $31.58 \%$ surgeries .Appropriate initial time of SAP was in $87.72 \%$ surgeries . Route, dose, dose interval were appropriate in all surgeries. The duration of prophylaxis was consistent with the guideline recommendation in $47.37 \%$ patients. SSI developed in $3.5 \%$ cases. Patients were discharged without complications.

Conclusion: Utilization of antimicrobials for surgical prophylaxis are not in accordance with standard treatment guidelines. There was overuse of antimicrobials .Costly and branded drugs were used. Effective educational intervention, development of local guidelines / protocols can help to overcome this.
\end{abstract}

Keywords: Antimicrobial, surgical prophylaxis, ASHP guidelines, surgical site infection.

\section{Introduction}

SSI are the infections related to operative procedure that occur at or around surgical incision within 30 days or up to 90 days depending on the operations. ${ }^{1,2}$ Infections of the surgical site are the common but avoidable complication of surgical procedure (nosocomial infection).Amongst nosocomial infections SSI is second to UTI. ${ }^{3}$ They are the main cause of morbidity and mortality in surgery. It may be serious with incidence of $2.5 \%$ in US. It is costly and is a burden on healthcare. ${ }^{4,5}$ Prevention of post-operative infections by all means is nowadays considered of paramount importance. Prophylaxis is administration of an antibiotic prior to contamination of previously sterile tissues or fluids (the use of antimicrobials for dirty and contaminated procedures is not considered prophylaxis). Pre-surgical prophylaxis is administration of an antibiotic when there is a strong possibility, yet unproven infection before surgery. Post-surgical prophylaxis is administration of an antibiotic when there is a strong possibility, yet unproven infection after surgery. ${ }^{6}$ SSI is preventable by applying surgical antimicrobial prophylaxis (SAP) strategy.

In US they account for $38 \%$ of nosocomial infections and 1 in 24 was post operative SSI (surgical site infection). In USA they cost 36 billion $\$ /$ year. ${ }^{7,8}$ It is underestimated in other countries due to poor data reporting.

Risk of SSI increases with contaminated surgeries, advancing age, hypothermia, co morbidities (DM, obesity, HIV), shaving of operative site, use of immunosuppressant's. ${ }^{9}$ They result in increased antimicrobial (AMA) usage, increased costs and prolonged hospitalization. Appropriate antibiotic prophylaxis can reduce the risk of postoperative wound infections. ${ }^{7}$

The ASHP guidelines are intended to provide standard approach to rational, safe and effective use of antimicrobials for prevention of SSI using evidence based strategies. ${ }^{10}$

Recently encounter with patients havingcomorbidities, emergence of antimicrobial resistance, increased cost make it challenging to treat SSI.

Despite knowledge of prevention of SSI progression in surgical technique, SSI is still one of the complications of surgeries.

Peri-operative antimicrobial use has long been advocated in certain clean and clean contaminated surgeries to decrease SSI. Guidelines published recently advocate one dose of narrow spectrum antimicrobial given 60 minute before surgery for preventing SSI. ${ }^{10}$ However surgeons do not comply with guidelines. They use broad spectrum antimicrobials and irrational FDCs. Such misuse is not free from harm to patient leading to increasing ADR, resistance, cost, superinfection. ${ }^{11}$ Recently in US public reporting about quality of surgery is made mandatory and reimbursement cost of SSI has been reduced. ${ }^{12}$ Inspite of guidelines, there is overuse, prolonged use, unnecessary use of AMA for SAP compliance of with guidelines is poor. Often 
discrepancy between available knowledge and clinical practice is noticed. Approximately half of SSI are preventable using one dose strategy without any dosing after 24 hours. SSI rate won't increase with fewer antimicrobial uses before and after implementation. Proper utilization of SAP reduces occurrence of SSI. ${ }^{4}$

In our hospital number of surgeries is rising, patients are seen with complex morbidities, which increases health care cost of SSI .Hence this study was carried out with aim at observing rational use of antimicrobials for SAP and adherence to ASHP guidelines.

\section{Materials and Method}

This is a prospective study carried out in 150 bedded tertiary care teaching hospital in tribal region of central India. The study duration was of 4 month from 15 Feb to 15 June 2018. The Institutional Ethics Committee approved the protocol. A total 228 patients admitted in general surgery ward and ICU were randomly selected. Operative notes were evaluated for demographic criteria, diagnostic criteria, history of comorbidity like obesity, diabetes, hypertension, allergy to AMA, co-medication like steroid use, type of surgery i.e. elective or emergency, type of wound classified as clean, clean-contaminated, contaminated, dirty, AMA selected, use of AMA like time of initial dose, intraoperative dose if any, time of postoperative dose, duration of SAP, route of administration, dose, type of antimicrobial used i.e. narrow spectrum, broad spectrum, duration of hospital stay were recorded on data entry sheet. Additional observations were made for any ADR occurrence, wound health, and infected wound, culture sensitivity report, by daily visit to ward/SICU. Patients who received AMA for preoperative/post-operative were excluded so also patients who developed wound infection postoperatively. Data collected were compared with parameters given in ASHP guidelines.

\section{Statistical analysis}

At the end of the study, all the data was pooled and expressed as counts and percentages or Mean \pm SD

\section{Results}

Table 1 shows demographic and surgical data of patients. Total 228 patients underwent various surgical procedures in this hospital during the period from 15 Feb to 15 June 2018. Their mean age was $38.74 \pm 17.03$ years ranging from 11 to 89 years. Three patients were above the age of 60 yrs. $81.58 \%$ were men and $18.42 \%$ were women .Patient with DM were $17.54 \%$, with hypertension were $48.68 \%$, with hypertension and DM both were $8.33 \%$ and with HIV were $0.9 \%$.Elective surgeries were $86.4 \%$, emergencies were $13.6 \%$, clean wounds $98.68 \%$, contaminated wounds $1.32 \%$, abdominal surgeries $60.96 \%$, urogenital $2.63 \%$, others $35.08 \%$, lump and cyst removal $1.32 \%$.
The highest number of surgeries were abdominal surgeries $(60.95 \%)$, urogenital $(35.09 \%)$, followed by others $(2.6 \%)$ and lump/cyst $(1.3 \%)$ surgeries. Most of the surgical wounds were clean wounds $(98.68 \%)$ while contaminated wounds were only $(1.32 \%)$.

Duration of hospital stay post-operatively was for 1 day in $(78.95 \%)$ patients, 2 days in $(14.47 \%)$ patients, 3- 5 days in $(5.70 \%)$ patients,> 5 days in $(0.9 \%)$ patients.

The mean duration of hospital stay was $(1.04 \pm 04)$ days pre-operatively and was $(1.316 \pm 06)$ days postoperatively. There was unnecessary SAP preoperatively in $22.80 \%$ respondents $87.71 \%$ cases received injectable AMA for prophylaxis, 60 minute before incision or induction of anesthesia. But in $12.3 \%$ it was started after 1 hour of surgery. Doses were appropriate adult doses only but not calculated considering the bodyweight of patient.

Table 2 depicts antimicrobials utilized in surgeries. Broad spectrum and combination preoperative were used in $4.82 \%$ patients and post operatively in $14.03 \%$ patients.

Total seven AMA viz. ceftriaxon 1G, FDC (piperacillin+tazobactum $4.5 \mathrm{G}$ ), (amoxicillin 500mg+ clavulanic acid $625 \mathrm{mg}$ ), metronidazole $500 \mathrm{mg}$, levofloxacin 400mg, ciprofloxacin 500mg, amikacin $500 \mathrm{mg}$ were used for antimicrobial prophylaxis. The antibiotic used most frequently were ceftriaxone in (228) $(100 \%)$, metronidazole (18) $(7.9 \%)$, amoxiclavin (14) (6.1\%), piperacillin-tazobactamin (13) (5.70\%), levofloxacin, amikacin, ciprofloxacin in (10) $(4.4 \%)$.received three or more than three instead of one agent were (216)(94.73\%)

All the antibiotics were administered intravenously. Surgery lasted for $>3$ hour in (09) $(3.90 \%)$ patients but only $(02)(0.9 \%)$ received intra operative dose of SAP. Pre-operatively in (134) $(58.77 \%)$ surgeries single dose AMA used was ceftriaxone $1 \mathrm{G}, 250 \mathrm{mg}$, 500mg and in (14) (6.14\%) patients. The two AMAs combinations included were ceftriaxone plus metronidazole / amoxicillin + clavulanic acid / amikacin / piperacillin+ tazobactam / levofloxacin / ciprofloxacin and piperacillin+tazobactum plus metronidazol. Unnecessary use was there in (138) (60.53\%) cases.

Intra-operative additional dose was given in (23) $(10.08 \%)$ surgeries. Duration of prophylaxis was less than 24 hours in (180) $(78.95 \%)$ surgeries and more than 24 hour in (48) $(21.05 \%)$ surgeries. It was up to two to five days in (46) (20.17) patients and more than five days in $(2)(0.9 \%)$ patients.

Post-operatively (23) (10.08\%) patients with surgery received single AMA i.e. ceftriaxone $1 \mathrm{gm}$, 500mg, 250mg, (181) (9.39\%) received two AMA (as above), (34) (14.91\%) patients received three AMA (ceftriaxone plus metronidazole plus (amoxicillin + 
clavulanic acid) / amikacin / surgeries. Appropriate initial time of SAP - (200) (piperacillin+tazobactum)/levofloxacin / ciprofloxacin/gentamicin). One patient also received four AMA (ceftriaxone plus metronidazole plus amikacin plus piperacillin+tazobactum). We found that antibiotics were used inappropriately for procedures for which antibiotic prophylaxis was not indicated.

Table 3 depict adherence to guidelines, there was appropriate antimicrobial selection in $72(31.58 \%)$

$(87.72 \%)$ surgeries.

Route, dose, dose interval were appropriate in (228) $(100 \%)$ surgeries. The duration of prophylaxis was consistent with the guideline recommendation in (108) $(47.37 \%)$ patients. SSI developed in (8) $(3.5 \%)$ despite SAP. All patients were discharged without complications.

Fig. 1 depicts the diagnosis of the patients who underwent surgery.

Table 1: Demographic and surgical data of patients $(n=228)$

\begin{tabular}{|l|c|}
\hline \multicolumn{1}{|c|}{ Patients characteristics } & Number of cases (\%) \\
\hline Mean age $( \pm$ SD $)$ & $38.74 \pm 17.03$ years \\
\hline Men & $186(81.58 \%)$ \\
\hline Women & $42(18.42 \%)$ \\
\hline Median stay & 01 day \\
\hline Pre-operative stay (mean \pm SD) days & $1.048 \pm 0.234$ \\
\hline Post-operative stay (mean \pm SD) days & $1.316 \pm 0.755$ \\
\hline Number of comorbidities & $111(48.68 \%)$ \\
\hline Hypertension & $40(17.54 \%)$ \\
\hline Diabetes Mellitus & $19(8.33 \%)$ \\
\hline Hypertension + Diabetes Mellitus & $139(60.96 \%)$ \\
\hline Type of procedure & $03(1.32 \%)$ \\
\hline Abdominal & $06(2.63 \%)$ \\
\hline Lump/cyst & $80(35.08)$ \\
\hline Urogenital & $197(86.40 \%)$ \\
\hline Miscellaneous & $31(13.60 \%)$ \\
\hline Type of surgery & $225(98.68 \%)$ \\
\hline Elective & 0 \\
\hline Emergency & $03(1.32 \%)$ \\
\hline Wound Class: & 0 \\
\hline Clean & \\
\hline Clean contaminated & \\
\hline Contaminated & \\
\hline Dirty &
\end{tabular}

Table 2: SAP utilization

\begin{tabular}{|l|c|c|}
\hline \multicolumn{2}{|c|}{ Name of AMA } & \multicolumn{2}{|c|}{ Number of cases (\%) } \\
\cline { 2 - 3 } & $\begin{array}{c}\text { Pre-operative } \\
(\mathbf{n = 2 2 8})\end{array}$ & $\begin{array}{c}\text { Post-operative } \\
(\mathbf{n = 2 2 8})\end{array}$ \\
\hline Single AMA & $02(0.88 \%)$ & $02(0.88 \%)$ \\
\hline Inj. Ceftriaxone 250 mg & $32(14.04 \%)$ & $06(2.63 \%)$ \\
\hline Inj. Ceftriaxone 500 mg & $104(45.61 \%)$ & $13(5.70 \%)$ \\
\hline Inj. Ceftriaxone 1 g & $14(6.14 \%)$ & $01(0.44 \%)$ \\
\hline Inj. Piperacillin-Tazobactum 4.5 g & 0 & $01(0.44 \%)$ \\
\hline Inj. Metronidazole 500 mg & $01(0.44 \%)$ & 0 \\
\hline Combination of 2 AMA & $01(0.44 \%)$ & 0 \\
\hline $\begin{array}{l}\text { (Inj. Amoxicillin +Clavulanic acid 625 mg)+ Inj. } \\
\text { Metronidazole 500 mg }\end{array}$ & $04(0.44 \%)$ & $27(11.84 \%)$ \\
\hline $\begin{array}{l}\text { Inj. Ceftriaxone 1 g + (Inj. Piperacillin + } \\
\text { Tazobactum 4.5 g) }\end{array}$ & \begin{tabular}{l}
$\mid$ \\
\hline $\begin{array}{l}\text { Inj. Ceftriaxone 500 mg + Inj. Metronidazole 500 } \\
\text { mg }\end{array}$
\end{tabular} \\
\hline Inj. Ceftriaxone 1 g + Inj. Metronidazole 500 mg & $56(24.46 \%)$ & $128(56.14 \%)$ \\
\hline Inj. Ciprofloxacin 500 mg + Metronidazole 500 & $01(0.44 \%)$ & $01(0.44 \%)$ \\
\hline
\end{tabular}




\begin{tabular}{|c|c|c|}
\hline $\mathrm{mg}$ & & \\
\hline $\begin{array}{l}\text { (Inj. Piperacillin }+ \\
+ \text { +Metronidazole } 500 \mathrm{mg}\end{array}$ & $01(0.44 \%)$ & $08(3.51 \%)$ \\
\hline Inj. Ceftriaxone 1g + Inj. Amikacin 500mg & 0 & $06(2.63 \%)$ \\
\hline $\begin{array}{l}\text { Inj. Ceftriaxone } 1 \mathrm{~g}+\text { Inj. Amoxicillin }+ \\
\text { Clavulanic acid } 625 \mathrm{mg} \text { ) }\end{array}$ & 0 & $01(0.44 \%)$ \\
\hline $\begin{array}{l}\text { Inj. Ceftriaxone } 500 \mathrm{mg}+\text { Inj. Levofloxacin } 400 \\
\mathrm{mg}\end{array}$ & 0 & $01(0.44 \%)$ \\
\hline Inj. Ceftriaxone $1 \mathrm{~g}+$ Inj. Levofloxacin $400 \mathrm{mg}$ & 0 & $01(0.44 \%)$ \\
\hline $\begin{array}{lcccc}\text { (Inj. Piperacillin + } & \text { Tazobactum } & 4.5 & \mathrm{~g})+ \\
\text { Metronidazole } 500 \mathrm{mg} & & & \end{array}$ & 0 & $08(3.51 \%)$ \\
\hline \multicolumn{3}{|l|}{ Combination of 3 AMA } \\
\hline $\begin{array}{l}\text { Inj. Ceftriaxone } 500 \mathrm{mg}+\text { Inj. Metronidazole } 500 \\
\mathrm{mg}+\text { Inj. Levofloxacin } 400 \mathrm{mg}\end{array}$ & 0 & $01(0.44 \%)$ \\
\hline $\begin{array}{l}\text { Inj. Ceftriaxone } 1 \mathrm{~g}+\text { Inj. Metronidazole } 500 \mathrm{mg} \\
+ \text { Inj. Levofloxacin } 400 \mathrm{mg}\end{array}$ & 0 & $05(2.19 \%)$ \\
\hline $\begin{array}{l}\text { Inj. Ceftriaxone } 500 \mathrm{mg}+\text { (Inj. Amoxicillin } \\
+ \text { +Clavulanic acid } 625 \mathrm{mg})+ \text { Inj. Metronidazole } \\
500 \mathrm{mg}\end{array}$ & 0 & $01(0.44 \%)$ \\
\hline $\begin{array}{l}\text { Inj. Ceftriaxone } 1 \text { g }+ \text { (Inj. Amoxicillin - } \\
\text { Clavulanic acid } 625 \mathrm{mg})+ \text { Inj. Metronidazole } \\
500 \mathrm{mg}\end{array}$ & 0 & $02(0.88 \%)$ \\
\hline $\begin{array}{l}\text { Inj. Ceftriaxone } 1 \mathrm{~g}+\mathrm{Inj} \text {. Metronidazole } 500 \mathrm{mg} \\
+ \text { Inj. Ciprofloxacin } 500 \mathrm{mg}\end{array}$ & 0 & $01(0.44 \%)$ \\
\hline $\begin{array}{l}\text { Inj. Ceftriaxone } 500 \mathrm{mg}+\text { Inj. Metronidazole } 500 \\
\mathrm{mg}+\text { Inj. Levofloxacin } 400 \mathrm{mg}\end{array}$ & 0 & $01(0.44 \%)$ \\
\hline $\begin{array}{l}\text { Inj. Ceftriaxone } 1 \mathrm{~g}+\mathrm{Inj} \text {. Metronidazole } 500 \mathrm{mg} \\
\text { + Inj. Levofloxacin } 400 \mathrm{mg}\end{array}$ & 0 & $04(1.75 \%)$ \\
\hline $\begin{array}{l}\text { Inj. Ceftriaxone } 500 \mathrm{mg}+(\text { Inj. Piperacillin }+ \\
\text { Tazobactam } 4.5 \mathrm{~g})+ \\
\text { Inj. Metronidazole } 500 \mathrm{mg}\end{array}$ & 0 & $01(0.44 \%)$ \\
\hline $\begin{array}{l}\text { Inj. Ceftriaxone } 1 \mathrm{~g}+\text { (Inj. Piperacillin }+ \\
\text { Tazobactam } 4.5 \mathrm{~g})+ \\
\text { Inj. Metronidazole } 500 \mathrm{mg}\end{array}$ & 0 & $04(1.75 \%)$ \\
\hline $\begin{array}{l}\text { Inj. Ceftriaxone } 1 \mathrm{~g}+\text { Inj. Metronidazole } 500 \mathrm{mg} \\
+ \text { Inj. Amikacin } 500 \mathrm{mg}\end{array}$ & 0 & $05(2.19 \%)$ \\
\hline $\begin{array}{l}\text { Inj. Ceftriaxone } 1 \mathrm{~g}+\text { (Inj. Piperacillin } \\
+ \text { Tazobactum } 4.5 \mathrm{mg})+ \\
\text { Inj. Amikacin } 500 \mathrm{mg}\end{array}$ & 0 & $01(0.44 \%)$ \\
\hline $\begin{array}{l}\text { Inj. Ceftriaxone } 1 \mathrm{~g}+\text { Inj. Metronidazole } 500 \mathrm{mg} \\
\text { + Inj. Gentamicin } 80 \mathrm{mg}\end{array}$ & 0 & $01(0.44 \%)$ \\
\hline $\begin{array}{l}\text { (Inj. Piperacillin +Tazobactum } 4.5 \mathrm{~g})+ \text { Inj. } \\
\text { Metronidazole } 500 \mathrm{mg}+ \\
\text { Inj. Amoxicillin-Clavulanic acid } 625 \mathrm{mg}\end{array}$ & 0 & $01(0.44 \%)$ \\
\hline $\begin{array}{l}\text { (Inj. Piperacillin +Tazobactum } 4.5 \mathrm{~g})+ \text { Inj. } \\
\text { Metronidazole } 500 \mathrm{mg}+ \\
\text { Inj. Levofloxacin } 400 \mathrm{mg}\end{array}$ & 0 & $06(2.63 \%)$ \\
\hline \multicolumn{3}{|l|}{ Combination of 4 AMA } \\
\hline $\begin{array}{l}\text { Inj. Ceftriaxone } 1 \mathrm{~g}+(\text { Inj. Piperacillin } \\
+ \text { Tazobactum } 4.5 \mathrm{~g})+ \\
\text { Inj. Amikacin } 500 \mathrm{mg}+\text { Inj. Metronidazole } 500 \\
\mathrm{mg}\end{array}$ & 0 & $01(0.44 \%)$ \\
\hline Unnecessary SAP & $44(19.30 \%)$ & $08(3.51 \%)$ \\
\hline \multicolumn{3}{|l|}{ Selection of SAP } \\
\hline Narrow spectrum AMA & $0 \%$ & $0 \%$ \\
\hline Broad spectrum AMA & 05 & 08 \\
\hline Combination of AMA & 06 & 24 \\
\hline
\end{tabular}




\begin{tabular}{|l|c|c|}
\hline Duration of SAP & \\
\hline$\leq 24$ hours & $218(95.61 \%)$ & $180(78.95 \%)$ \\
\hline$>24$ hours & $10(0.44 \%)$ & $48(21.05 \%)$ \\
\hline
\end{tabular}

Table 3: Duration for which antimicrobial agents (AMAs) were used in each patient in pre-operative and post-operative period $(n=228)$

\begin{tabular}{|l|c|c|}
\hline $\begin{array}{c}\text { Duration for which } \\
\text { AMAs were used }\end{array}$ & $\begin{array}{c}\text { Pre-operative period } \\
\text { No. of cases (\%) }\end{array}$ & $\begin{array}{c}\text { Post-operative period } \\
\text { No. of cases (\%) }\end{array}$ \\
\hline 1 day & $218(95.61 \%)$ & $180(78.95 \%)$ \\
\hline 2 days & $09(3.95 \%)$ & $33(14.47 \%)$ \\
\hline 3 to 5 days & $01(0.44 \%)$ & $13(5.70 \%)$ \\
\hline 6 to 10 days & 0 & $02(0.88 \%)$ \\
\hline
\end{tabular}

Table 4: SAP parameters and Compliance with ASHP guidelines $(n=228)$

\begin{tabular}{|l|l|}
\hline \multicolumn{1}{|c|}{ Parameter } & \multicolumn{1}{c|}{$\mathbf{n}(\mathbf{\%})$} \\
\hline Correct choice of AMA & $72(31.58 \%)$ \\
Correct time of initial dose of AMA & $200(87.72 \%)$ \\
Correct dose & $228(100 \%)$ \\
Correct route of administration & $228(100 \%)$ \\
Correct duration of prophylaxis & $108(47.37 \%)$ \\
Unnecessary use of & $130(57.02 \%)$ \\
Compliance with all parameters & $44(19,30 \%)$ \\
\hline
\end{tabular}

Compliance with the American Society of Health-System Pharmacists (ASHP) guidelines on antimicrobial prophylaxis to prevent SSI in surgery. $(n=228)$

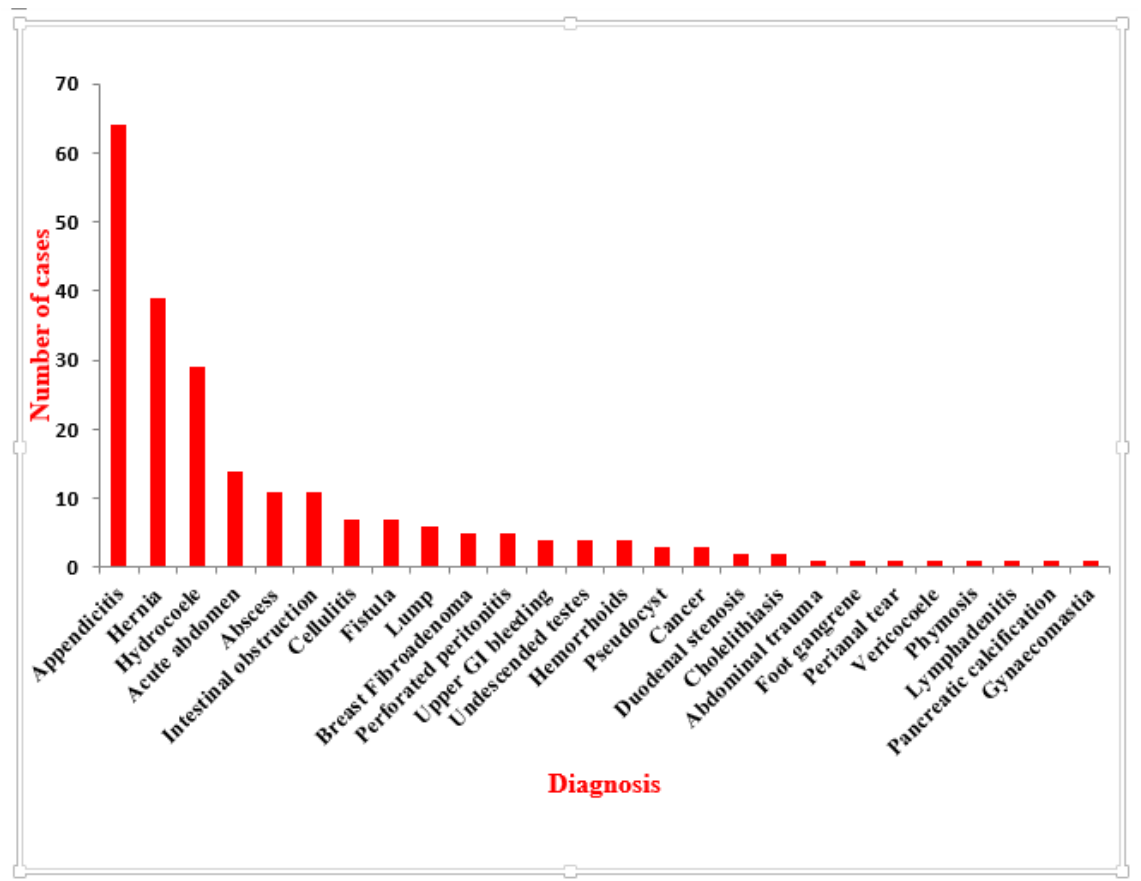

Fig. 1: Diagnosis of the patients who underwent surgery

\section{Discussion}

In this prospective study, data from total 228 surgical records of patients who underwent surgery were evaluated from $15 \mathrm{Feb}$ to 15 June 2018. The data were evaluated for the practice of surgical antimicrobial prophylaxis with respect to compliance with ASHP guidelines in surgery ward of 150 bedded tertiary care teaching hospital in tribal region central India. We looked at adherence to guidelines and rational use of antimicrobials for surgical prophylaxis. Observing adherence to guidelines can enhance the quality of antibiotic use.

The result of our study observed that all 228 patients who underwent surgery received surgical antimicrobial prophylaxis (SAP). Men underwent more surgeries (186) $(81.58 \%)$ than women (42) $(18.42 \%)$. 
Abdominal surgeries were higher in men (102) $(44.74 \%)$ while urological surgeries were more $(84)$ $(36.84 \%)$ in women. Most surgeries were clean (225) $(98.68 \%)$ and elective (187) (82.02\%), while contaminated surgeries were only (03) (1.32\%), emergencies were (31) (13.60\%). Larger chunk were of abdominal surgeries (138) (60.53\%), followed by urogenital surgeries (80) (35.10\%), other surgeries (06) $(2.63 \%)$ and lump/cyst (03) $(1.32 \%)$ removals. In many records proper medical history or treatment was not entered. Co-morbidities were DM, hypertension, HIV, obesity.

Minimal hospital stay for pre-operative was (1.048 $\pm 0.238)$ and for post-operative was $(1.316 \pm 0.7)$. Reasons of reduced stay may be that most were clean surgeries.

ASHP guidelines recommend inj. Cefazolin $1 \mathrm{G}$ $(25 \mathrm{mg} / \mathrm{kg})$ as a single dose for initial dosing in most of the clean and contaminated surgeries. Single preoperative dose of antibiotic is as effective as full five days course of therapy assuming uncomplicated procedure. Antibiotics should be administered within 1 hour prior to incision, preferably with induction of anesthesia. Prophylactic antibiotics should target anticipated organisms to have reliable and predictable serum or tissue concentration. For vancomycin the dosing time should be within 120 minutes of incision. In this hospital all surgical procedures (228) (100\%) exactly followed the time frame of prophylactic use but was not properly documented in post-operative notes. Single dose prophylaxis has the following advantages viz. Reduced side effects, reduced total amount of antibiotics used, reduced work load, reduced duration of hospitalization, reduced amount of waste material generated and reduced total $\operatorname{costs}^{[13]}$.Prophylactic antimicrobial should be given in clean surgery which involves prosthetic implants, in clean-contaminated and contaminated surgeries. Prophylactic antimicrobials should be administered within 1 hour prior to incision. Therapeutic antibiotic should be started for dirty wound and then empirical therapy should be altered according to the sensitivity of the culture. Doses used were appropriate but not according to per kg body weight. These findings are in correlations with findings of Whitney JG. et al. ${ }^{14}$

Surgeon knew that the use of antimicrobial prophylaxis is to prevent surgical site infection (SSI) but pays no attention to National and International guidelines. ${ }^{15}$ In this study all criteria's mentioned in the guidelines were observed in (22) $(9.65 \%)$ surgeries only.

All antimicrobials (total 7) used were administered IV as a single large dose in all $228(100 \%)$ surgeries but as per guidelines dosing should be weight based. High dose of IV cefazolin should be used for persons weighing more than $120 \mathrm{~kg}$. Here adult doses were used for all patients. In this study for initial dosing third generation cephalosporin (IV ceftriaxone 1G, 500mg, 250mg) was used mostly as single dose in maximum patients $(148)(64,91 \%)$ followed by (IV piperacillin +tazobactum $4.5 \mathrm{G}$ ) single dose in (14) $(6.14 \%) \%$, post -operatively same continued in (23) $(10.08 \%)$. Both of the above antimicrobials are not effective against staph aureus. Narrow spectrum IV cephazol in $1 \mathrm{G}$ should be the choice as its spectrum is against Gram +ve bacteria including staph. Aureus which is implicated in SSI. The use of antimicrobial not recommended for prophylaxis, are the most common errors in antibiotic selection. Such inappropriate selection of antibiotics for prophylaxis has been shown in other studies also. ${ }^{16-19} \mathrm{In}$ (44) $(19.30 \%)$ surgeries, pre-operative antimicrobial was not needed as they belonged to clean surgeries without any associated risk factors. Some other studies also reported appropriate selection of antibiotics and its use for prophylaxis in surgeries. ${ }^{20,21}$

Repeat dose of same pre-operative AMA was administered in (186) (81.58\%) surgeries, including abdominal (154) (67.54\%) and urogenital (32) $(14.04 \%)$. Intra-operative dose was used in surgeries lasting more than 4 hours or if there is excessive blood loss but that was not properly documented in case records of the patients. Such findings have also been reported by other studies. ${ }^{19}$

Duration of antimicrobial prophylaxis was extended more than 3- 5 days in (48) $(21.05 \%)$ surgeries. The reason of this extended use may be that most of these surgeries were abdominal, urogenital, gut or biliary. Guidelines recommend use of IV cefuroxime $1.5 \mathrm{G}(35 \mathrm{mg} / \mathrm{kg})$ plus IV metronidazole $500 \mathrm{mg}$ $(10 \mathrm{mg} / \mathrm{kg})$ or IV gentamicin $160 \mathrm{mg}(3 \mathrm{mg} / \mathrm{kg})$ plus metronidazole $500 \mathrm{mg}(10 \mathrm{mg} / \mathrm{kg})$ for pre-operative as well as intra-operative use in such surgeries as single dose. Specimen was not collected for culture sensitivity. This was in agreement with other studies. ${ }^{22-}$ 24

In the present study duration of anti-microbial prophylaxis extended beyond single dose after 24 hours. It was more than 24 hours post-operatively in $148(64.91 \%)$ cases while in $180(78.95 \%)$ cases it was within 24 hours. Same inappropriateness had been reported by other studies. ${ }^{25,26}$ Extended use have been linked with superinfection with clostridium difficile, bacterial resistance and toxicity. ${ }^{27-29}$ Reason may be incomplete knowledge of prophylaxis guidelines, occurrence of frank post- operative bacterial infection of the wound or any other systemic infection or may be because most of the surgeries were abdominal and urogenital. Proper documentation was not made. There is wrong conception that prolong use will prevent SSI effectively. Post-operative course should be short, treated with single dose, duration should be less than 24 hour regardless if there is indwelling drains, as per 2017 guidelines. Similar observations are reported in other studies. $^{30}$

In the present study pre-operatively (227) (99.56\%) patients received antimicrobials for $1-5$ days, may be to 
control infection at the time of hospital admission but was not properly documented in case record. Wrong selection was noticed in (25) $(12.44 \%)$ pre-operative cases and (66) (32.84\%) in post-operative cases.

Choice of antimicrobial is dictated by likely pathogenic contaminant. Goal of surgical antimicrobial prophylaxis should be to reduce incidence of SSI, minimal disturbance of normal flora, reduction in ADR, decrease resistance, increase cost effectiveness. Wrong antibiotic use was in (91) (39.91\%) patients. Reason may be high patient load, complexity of surgery, incomplete knowledge of antimicrobials, defunct microbiological lab functioning. Wrong choice of antimicrobial is also reported by other studies. ${ }^{31,32}$ There is need of continuing medical education for surgeons.

$36 \%$ patients received appropriate antimicrobials but use of more than one drug and use of nonrecommended antimicrobial like $3^{\text {rd }}$ generation cephalosporins are common errors encountered in antimicrobial selection. Such overuse/misuse leads to bacterial resistance ${ }^{32}$ and increased healthcare cost. ${ }^{33}$ Inappropriate selection also shown in other studies across the world ${ }^{30}$ appropriate selection was there in US [31], China, ${ }^{32}$ Brazil. ${ }^{33}$

Thirteen patients developed infection of the wound during hospitalization inspite of AMA use.

There was excessive and inappropriate use of IV ceftriaxone despite availability of guidelines. Ceftriaxone was used as a single agent in high risk biliary surgeries or with metronidazole in colorectal surgeries. As per guidelines narrow spectrum antimicrobial against likely pathogens including staphylococcus aureus is injection cephadroxil 1 gram $(50 \mathrm{mg} / \mathrm{kg})$ or oral cephalaxine 1 gram $(50 \mathrm{mg} / \mathrm{kg}$ ) or IV cephazoline 2 gram $(20 \mathrm{mg} / \mathrm{kg})$. In Penicillin allergy IV clindamycin Ares $600 \mathrm{mg}(20 \mathrm{mg} / \mathrm{kg})$ and in MRSA prevalent areas IV vancomycin $1 \mathrm{mg}(20 \mathrm{mg} / \mathrm{kg})$ should be used instead of cephalosporin. ${ }^{29}$ Use of broad spectrum antimicrobials or antimicrobial combinations would lead to lack of response, increased cost and will foster resistance..$^{32}$ Rampant use of broad spectrum antimicrobials or antimicrobial combinations is a false belief of more effectiveness in prevention of SSIs in surgeries. Non availabilities of hospital supplies of antimicrobials may have contributed to inappropriate selection. Often selection was based on surgeon's experience, local knowledge of prevalent pathogens and local resistance pattern was not considered or was not available. These findings were consistent with the findings of other study. ${ }^{34}$

Third generation cephalosporin (IV ceftriaxone) along with IV metronidazole and IV amikacin was used in (34) $(14.91 \%)$ patients to cover gram positive, gram negative aerobes and anaerobes. But spectrum of both ceftriaxone and amikacin is against gram negative organisms only. No significant difference in efficacy was noticed by many studies using such combinations.
Broad spectrum antimicrobial use or use of antimicrobial combination was made in $11(4.28 \%)$ preoperative and $32(14.03 \%)$ post -operative patients. Preoperative single agent was ceftriaxone (148 patients) or piperacilline+tazobactam (14 patients). Combination of 2 anti-microbials consisted of ceftriaxone+ metronidazole/piperacilline +tazobactum/amikacin/ levofloxacin/amoxicillin clavulanic acid/ciprofloxacin in $14(6.14 \%)$ patients. In post-operative cases single agent was ceftriaxone in $23(10.08 \%)$ patients. Combination of 2 anti-microbials consisted of ceftriaxone + metronidazole/piperacilline +tazobactum/levofloxacin/amoxacillin clavulanic acid/ciprofloxacin in 181 patients (79.38\%). Combination of 3 antimicrobials was ceftriaxone + metronidazole + piperacillin + tazobactam/levofloxacin/amoxacillin+clavulanic acid/ciprofloxacin was in 34 patients $(14.91 \%)$ and combination of 4 antimicrobials consisted of ceftriaxone, metronidazole, piperacillin + tazobactam, amikacin. Use of such irrational combinations may be because of more urogenital or colorectal operations.

Nowhere the selection of antimicrobials for post operative use was based on culture sensitivity reports. Kreisel et al showed positive relation between inappropriate SAP and clostridium difficile toxin in 357 patients. ${ }^{32}$

In 218 patients antimicrobials were started at admission empirically 1 day before, 2 days before ( 9 patients) or 3-5 days before (1 patient) before operation. Duration of post- operative use was 1 day (180 patients), 2 days (33 patients), 3-5 days (13 patients), 610 days (2 patients). This may be because of frank infection post operatively or lack of knowledge that for clean surgeries there is no need of extending use beyond 24 hours, that too frequently changing different combinations with no rationality, blindly without doing culture and sensitivity for definitive therapy. SSI if occur post-operatively remain sensitive to same prophylactic antimicrobials. Brand names were used for prescribing antimicrobials like pipzo, taza, monocef, etc.

Risk factors for SSI include poor hygiene, co morbid conditions like DM/malnutrition/ advancing age/ inadequate wound immobilization. There are studies showing substantial cost reduction with less antimicrobial use or SAP. Open distal pancreatectomy (ODP) showed reduced cost without increasing SSI rate in poorly funded regions. Even relatively modest savings can have great impact. Implementing appropriate prophylactic program have been a great success, but often incorrect low compliance to guidelines. ${ }^{6,17}$

New guidelines does not recommend vancomycin as a drug of choice for any procedure. It may be included if MRSA have been detected at institution or considered for patients with high risk of MRSA colonization. Vancomycin is less effective than 
cefazoline for prevention of infection with MSSA .Intranasal mupirocin is indicated for $s$. aureus colonization in cardiac patients or elective orthopedic procedures known to be colonized or infected with MRSA/MSSA. ${ }^{33}$

The present study concludes that prescribing and utilization of antibiotics for surgical prophylaxis are not in accordance with standard treatment guidelines. There was inappropriateness in AMA use in terms of wrong choice, over and prolonged use, using costly, with brand names. Remedy to this will be that institution should endeavor in developing local guidelines and protocols for surgical antimicrobial prophylaxis. Local guidelines should be based on local bacterial pattern and best evidence in literature. This would facilitate rational prescribing and utilization of antimicrobial for surgical prophylaxis.

Another step towards rationality would be effective educational intervention through authoritative senior doctors. Committee supervising hospital antibiotic policy and hospital infection control measures should be made functioning.

Good aseptic precautions and good surgical techniques will go a long way in preventing the SSIs. The poor practice documented by the present study could be enhanced with effective interventions

\section{Limitations}

The sample size of this study was small. Medical records were not properly maintained in this hospital. Long term follow up to assess SSI outcome was not done. Cost effectiveness was not done.

\section{Finance and sponsorship: Nil.}

Conflict of interest: None to declare.

\section{References}

1. Sandra I. et al .Centers for Disease Control and Prevention Guideline for the Prevention of Surgical Site Infection. JAMA Surg 2017;152:784-92.

2. Anderson DJ et al. Antimicrobial prophylaxis for prevention of surgical site infection in adults.https://www.uptodate.com/.../antimicrobialprophylaxis-for-prevention-of-surgical-sit. Mar 9, 2018

3. Khan HA et al. Nosocomial infections: Epidemiology, prevention, control and surveillance Asian 2017;7(5):47882.

4. Coomer NM, Kandilov AM. Impact of hospital-acquired conditions on financial liabilities for Medicare patients. Am J Infect Control 2016;44:1326-34.

5. Anderson DJ et al. Strategies to prevent surgical site infections in acute care hospitals. Infect Control Hosp Epidemiol 2014;35:605-27.

6. Hawn MT et al. Timing of Surgical Antibiotic Prophylaxis and the risk of SSI. JAMA 2013;148(7):64957.

7. Bratzler DW et al. Clinical practice guidelines for antimicrobial prophylaxis in surgery. American Journal of Health-System Pharmacy.2013;70(3):195-283.

8. Abubaker IE et al Prophylactic Antibiotics and Wound Infection. J ClinDiagn Res. 2013;7(12):2747-27.
9. Keith S. Kaye, SorabhDhar. Infection Prevention and Control in Healthcare, Part II: Epidemiology \& Prevention of Infections. December 2016.

10. ASHP Therapeutic Guidelines on Antimicrobial Prophylaxis in Surgery. Developed through the ASHP Commission on Therapeutics \& approved by the ASHP Board of Directors on April 21, 1999 American Society of Health-System Pharmacists.

11. Michael S et al .Surgical Site Infections VolumeOutcome Relationship and Year-to-Year Stability of Performance Rankings. Medical Care 2017;55(1):79-85.

12. Umscheid CA et al. Estimating the proportion of healthcare-associated infections that are reasonably preventable and the related mortality and costs. Infect Control Hosp Epidemiol 2011;32(2):101-14.

13. John Shepard et al. Financial Impact of Surgical Site Infections on Hospitals. The Hospital Management Perspective. JAMA Surg 2013;148(10):907-14.

14. Whitney JG et al.Assessment of Prophylactic Antibiotic Use in Patients with Surgical Site Infections. Hospital pharmacy. 2013;48(7):560-7.

15. Lallemand $\underline{S}$ et al. Non-observance of guidelines for surgical antimicrobial prophylaxis and surgical-site infections. Pharma World Sci 2002;24(3):95-9.

16. Elbur AI et al. An audit of prophylactic surgical antibiotic use in a Sudanese Teaching Hospital. Int J Clin Pharm 2013;35:149-53.

17. Goede WJ et al. Assessment of prophylactic antibiotic use in patients with surgical site infections. Hosp Pharm 2013;48:560-7.

18. Ru Shing Ng et al. Surgeons' adherence to guidelines for surgical antimicrobial prophylaxis - A review. Australas Med J 2012;5(10):534-40.

19. Hendren S1 et al. Antibiotic choice is independently associated with risk of surgical site infection after colectomy: a population-based cohort study. Ann Surg 2013;257(3):469-75.

20. HeineckI et al. Prescribing practice for antibiotic prophylaxis for 3 commonly performed surgeries in a teaching hospital in Brazil. Am J Infect Control 1999;27:296-300.

21. Ou Y, Jing BQ et al. Audits of the quality of perioperative antibiotic prophylaxis in Shandong Province, China, 2006 to 2011. Am J Infect Control 2014;42:516-20.

22. Miliani K.et al. INCISO Network Study Group. Noncompliance with recommendations for the practice of antibiotic prophylaxis and risk of surgical site infection: results of a multilevel analysis from the INCISO Surveillance Network. J Antimicrob Chemother 2009;64(6):1307-15.

23. Durando $\mathrm{P}$ et al. Adherence to international and national recommendations for the prevention of surgical site infections in Italy: Results from an observational prospective study in elective surgery. Am J Infect Control 2012;40:969-72.

24. Afhami SH et al . Antibiotic prophylaxis before surgeries. Iran Surg J 2011;19:28-35.

25. National Healthcare Safety Network, Centers for Disease Control and Prevention. Surgical site infection (SSI) event. http://www.cdc.gov/nhsn/pdfs/pscmanual/9pscssicurrent. pdf

26. Engelmann JJ et al. Adverse clinical and economic outcomes attributable to methicillin resistance among patients with Staphylococcus aureus surgical site infection. Clin Infect Dis 2003;36(5):592-98. 
27. Salkind AR et al. Antibiotic Prophylaxis to Prevent Surgical Site Infections. Am Fam Physician 2011;83(5):585-90.

28. Aubrey Balch et al.Antibiotic prophylaxis for surgical site infections as a risk factor for infection with Clostridium difficile 2017;12(6):e0179117.

29. Alavi SM et al.Antibiotics Use Patterns for Surgical Prophylaxis Site Infection in Different Surgical Wards of a Teaching Hospital in Ahvaz, Iran Jundishapur J Microbiol 2014;7(11):e12251

30. Bedouch $\mathrm{P}$ et al. Compliance with guidelines on antibiotic prophylaxis in total hip replacement surgery: results of a retrospective study of 416 patients in a teaching hospital. Infect Ctrl Hosp Epidemiol 2004;25(4):302-7.

31. Vaisbrud V et al. Surveillance of antimicrobial prophylaxis for surgical procedures. Infect Control Hosp Epidemiol 1999;20:610-3.

32. Ou Y et al. Audits of the quality of perioperative antibiotic prophylaxis in Shandong Province, China, 2006 to 2011. Am J Infect Control 2014;42:516-20.

33. Trautmann $\mathrm{M}$ et.al. Intranasal mupirocin prophylaxis in elective surgery. A review of published studies. Chemotherapy.2008;54(1):9-16.

34. Wright TI et al. Antibiotic prophylaxis in dermatologic surgery: advisory statement 2008. J Am Acad Dermatol 2008;59(3):464-73. 